\title{
Vehicular Wind Energy Converter (VWEC): A Solution to Sustainable Charging For Electric Vehicles
}

\author{
A. A. Dare ${ }^{1}$, D. C. Uguru-Okorie ${ }^{2}$ and A. A. Adegbola ${ }^{3}$ \\ ${ }^{1}$ The Department of Mechanical Engineering, University of Ibadan, Nigeria. \\ ${ }^{2}$ The Department of Mechanical Engineering, Landmark University, Omu-Aran, Nigeria. \\ ${ }^{3}$ The Department of Mechanical Engineering, Ladoke Akintola University of Technology, Ogbomoso.
}

\begin{abstract}
The present energy situation and the pollutions from vehicles running on internal combustion engines in the world have necessitated the need to harness energy from other unconventional sources to power them. Electric Vehicles have been developed to solve this problem, but a sustained energy supply to run these vehicles have been a major drawback. Wind energy from a moving vehicle as one of such unconventional sources could be harnessed and subsequently used to power these vehicles. This paper is directed at the design and numerical modeling of a device for harnessing wind energy from a moving vehicle, which the author called a Vehicular Wind Energy Converter (VWEC). The results from the model show the potential of this device as an on-board charging system for Electric and Hybrid Vehicles.
\end{abstract}

Keywords: Charging, Electric Vehicle, Emission, Vehicle Speed, Wind Energy

\section{Introduction}

An electric vehicle is an electrical energy powered vehicle that uses one or more electric motors or traction motors for propulsion. Examples of electric vehicles are trolley buses, electric cars, electric trains etc.

Electric vehicles which exist are powered in three main ways [1]:-

$>$ By stored electrical energy in batteries, which were already charged from an external station.

$>$ Directly powered from an external power station

$>$ Powered by an on-board electrical generator as seen in hybrid electric vehicles or hydrogen fuel cell.

With the increase in the concern of the environmental pollution generated by internal combustion engines, stringent measures have been taken by governments to ensure vehicle manufacturers design fossil fuel engines that conform to the stipulated emission standards.

With the high demand of internal combustion engine vehicles as a result of the increasing population of mankind, it is observed that more emission than the atmosphere can handle are being emitted which has led to the environmental problems in the world. The development of Electric vehicles is the solution to the problem posed by internal combustion engines emissions.

\subsection{Energy Source for Charging and Powering Electric Vehicles}

The electrical energy source for charging/recharging the batteries of Electric Vehicles have had its major source from Internal Combustion engines running on fossil fuel, Nuclear Reactors, Coal powered plants etc, which all have toxic by-products harmful to human and the environment. The dwindling reserves of these non-renewable fuels and the adverse environmental effect of its by-products have necessitated the need to harness energy from other unconventional sources. Wind energy from a moving vehicle as an unconventional source could be harnessed and subsequently used in electric vehicles and thereby prolonging its mile per charge.

This paper looks at the potentials of a vehicular wind energy converter in producing electric energy for sustained powering of electric and hybrid vehicles. This energy is produced when a vehicle is in motion and it is used to power the vehicle and also to charge the batteries, which store the energy for later use.

The vertical axis wind turbine is basically divided into two types: (a) The lift-type (Darrieus type) and (b) the drag-type (Savonius type) [2][3].

\subsection{Objective}

$>$ To design a charging system for electric vehicles that extracts energy from the wind moving over a vehicle in motion to charge its batteries. 


\section{Device Description}

The authors of this paper have proposed a designed device called the vehicular wind energy converter as an on-board charging device for the electric vehicle batteries, because of its potential of relatively high power output.

The vehicular wind energy converter is a three-bladed, drag type vertical axis wind turbine which generates electrical energy from the wind moving over a vehicle in motion while the . The device is an enclosed device which has only the inlet and exit openings. The tapering inlet opening is designed in such a way as to focus the inlet wind on the blade and also to amplify the wind velocity to about 1.4 times before it hits the blades and the external casing of the device is streamlined to reduce drag.

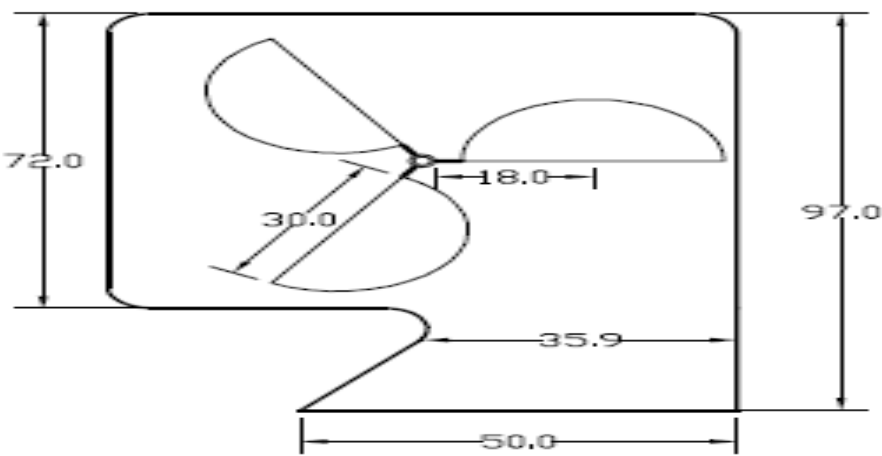

Fig 1: The plan view of the Vehicular Wind Energy Converter (VWEC)

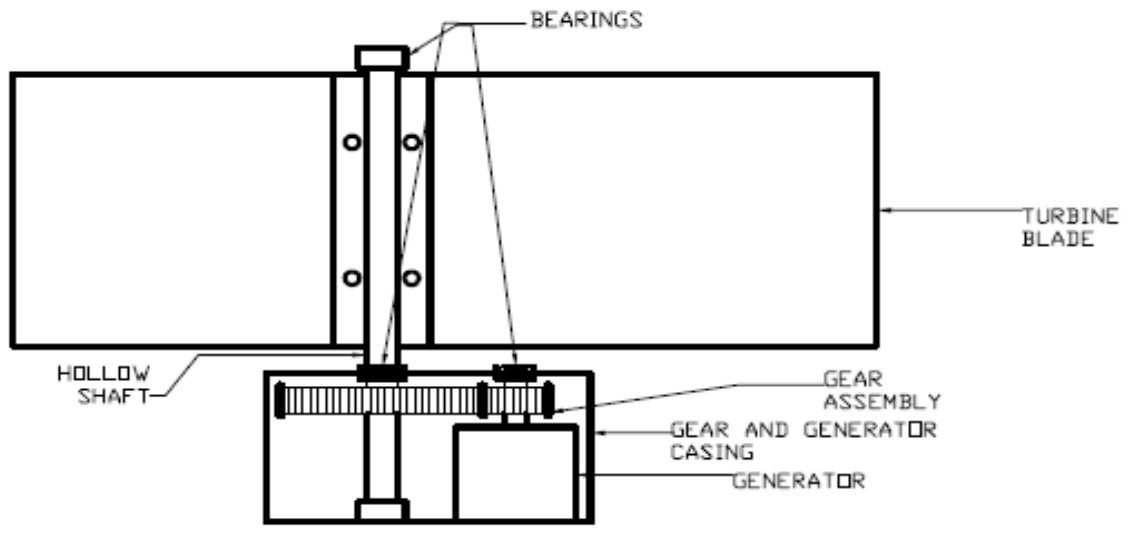

Fig 1a: Parts of the Vehicular Wind Energy Converter (VWEC)

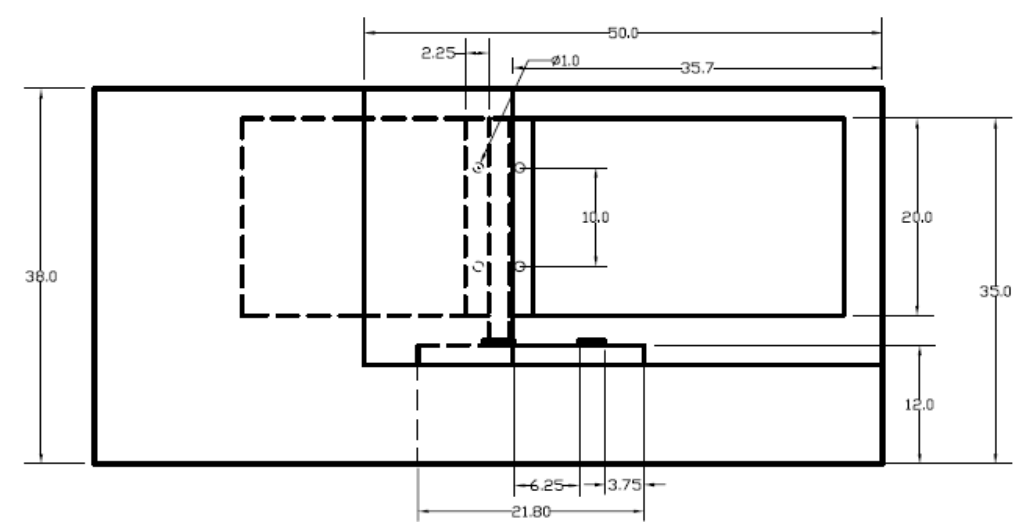

Fig 1b: The front View of the device (VWEC)

\subsection{The choice of a the vertical axis design format}

The reduced height of a vertical axis design format of wind turbine compared to the horizontal axis design, the simplicity in its design, its self starting ability as is seen in the Savonius were considered. Also based on previous research conducted by Uguru-Okorie [4]; it seen that the vehicular wind energy converter has a great potential as power source for charging the Electric Vehicles batteries. Since the device operates on the relative velocity between the air and the vehicle speed, the disadvantage of access to high wind speed is eliminated. 


\section{The Design Of The Vehicular Wind Energy Converter}

The vehicular Wind Energy Converter is a drag-type (three-bladed) vertical axis wind turbine (Savonius rotor type).

The Savonius rotors work at a lower tip speed ratio and have been reported from tests to have a peak efficiency of 31 percent under the wind tunnel test and 37 percent in the free air stream [5]. In most tests conducted on the Savonius rotor, efficiencies ranging from 25 to 35 percent have been reported [6][7]. Qasim, Usubamatov and Zain, [8] observed an increase of the power coefficient $C_{p}$ of a drag type vertical axis with an increase on the surface drag of the Turbine blades.

The power $P$ in the wind is given by [9]:

$$
P=\frac{1}{2} \alpha \rho \pi r^{2} v^{3}
$$

Where,

$\mathrm{P}=$ power in watts, $\alpha=$ an efficiency factor determined by the design of the turbine, $\rho=$ mass density of air in kilograms per cubic meter, $r=$ radius of the wind turbine in meters, and $v=$ velocity of the air in meters per second.

For a Savonius rotor of height $\mathrm{H}$, a wind velocity $v$, the extractable mechanical power $\mathrm{P}$, and the mechanical torque $\mathrm{T}$, on the axis can respectively be written as follows[8][9]:

$\mathrm{P}=1 / 2 \mathrm{C}_{\mathrm{p}} \rho \mathrm{rH} v^{3}$

and $\mathrm{T}=\mathrm{C}_{\mathrm{m}} \mathrm{\rho r}^{2} \mathrm{H} v^{2}$

3

where $\mathrm{C}_{\mathrm{p}}$ and $\mathrm{C}_{\mathrm{m}}$ are respectively the power coefficients and torque coefficients.

\subsection{Design of Device Electrical Energy Generator}

The kinetic energy in the wind is converted to electrical energy by the wind turbine generator, which is channeled to the right source for use.

Most of the wind turbines are equipped with induction generators. They are simple and rugged in construction and offer impressive efficiency under varying operating conditions. Induction machines are relatively inexpensive and require minimum maintenance and care. Characteristics of these generators like the over speed capability make them suitable for wind turbine application. As the rotor speed of these generators is not synchronized, they are also called asynchronous generators [6].

For the design, a six pole induction generator was considered because it has a lower synchronous speed of $1000 \mathrm{rpm}$ as against the four poles that has a synchronous speed of $1500 \mathrm{rpm}$ [6], this will allow the use of a smaller gearbox and thereby reducing loses in transmission.

\subsection{Design of Gearbox}

For the generator of a wind turbine to be able to generate electric energy, it has to rotate at speeds ranging from $1000 \mathrm{rpm}$ to $1500 \mathrm{rpm}$ depending on its designed synchronous speed.

Due to the low tip speed ratio $(\lambda)$ of a vertical axis wind turbine, $(\lambda \leq 1)$, a gear box is needed to achieve the synchronous speed for the wind turbine electrical generator. The right gear box is needed to for the production of electrical energy at the minimum designed wind speed.

\subsubsection{Gear Ratio Design}

$$
\text { Recall: } \lambda=\frac{\omega r_{e}}{V}
$$

Where,

$$
\lambda=\text { lower tip speed, } \omega=\text { Angular speed in } \mathrm{rpm}, \mathrm{V}=\text { Wind velocity }(\mathrm{m} / \mathrm{s})
$$

From the test conducted by [7], with the same type of Savonius Rotor blades, the lower tip speed of the blade was measured to be 0.65 based on this, for this design, a lower tip speed ratio $(\lambda)$ of 0.6 was chosen, $\lambda=0.6$, velocity of wind $v=6 \mathrm{~m} / \mathrm{s}$, and Rotor radius $\mathrm{r}=0.40 \mathrm{~m}$.

The Angular speed in rpm $(\omega)=\frac{\lambda V}{r}=\frac{0.6 \times 6}{0.40}=9 \mathrm{rev} / \mathrm{sec}=540 \mathrm{rpm}$

The gear ratio

$=\quad \frac{\text { Generator synchronous speed in } \mathrm{rpm}}{\text { Estimated turbine shaft speed in rpm }}=$
$=\frac{1550}{540} \approx 2.87$

A gear box of ratio 3:1 was chosen for the design. 


\section{Field Survey}

The dimensions of the width, length and height of the roof of some vehicle in Ibadan metropolis where taken [4]. The results are shown in Fig 2 below.

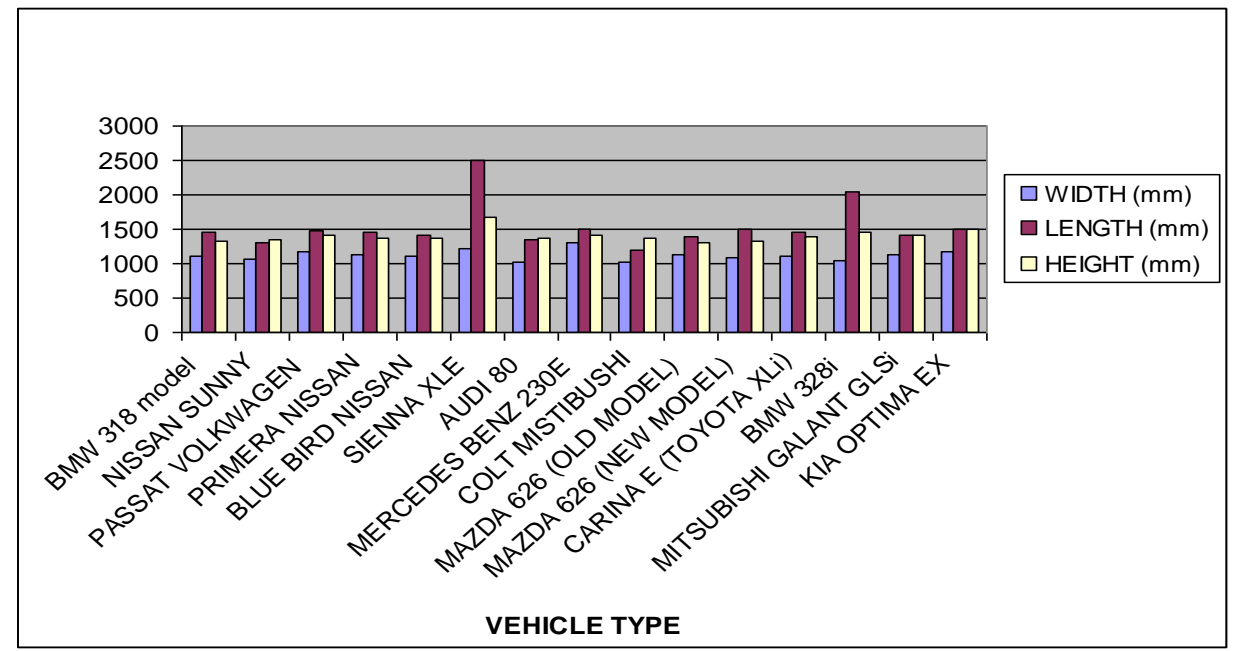

Figure 2: A Chart of the Dimensions of the Roof of Some of the Vehicles Surveyed

Figs 3 and 4 show the ranges of width and length the vehicles in Ibadan metropolis and their frequencies.

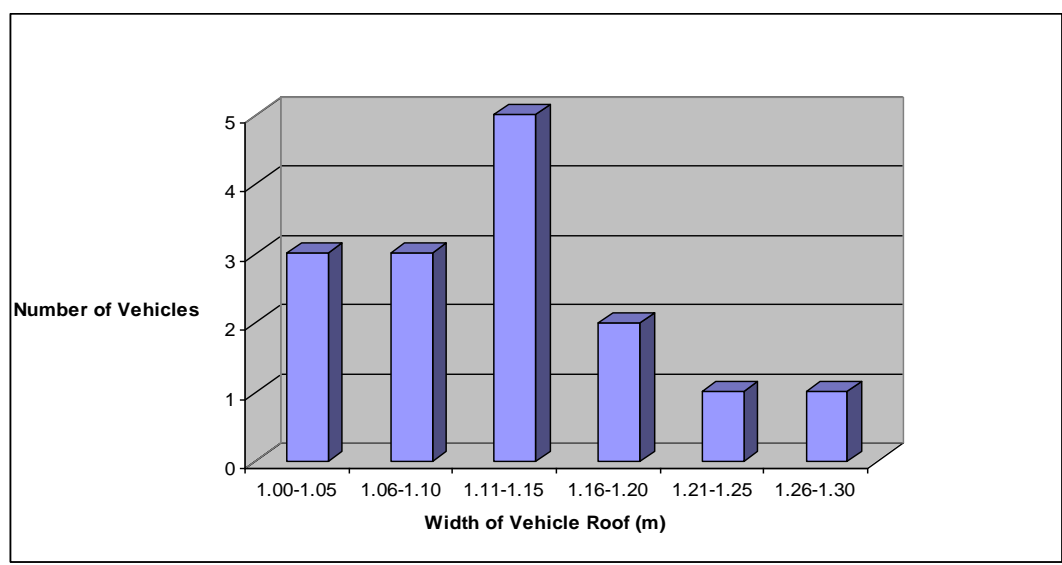

Figure 3: A Chart Showing the Number of Vehicles Surveyed to the Ranges of their Width

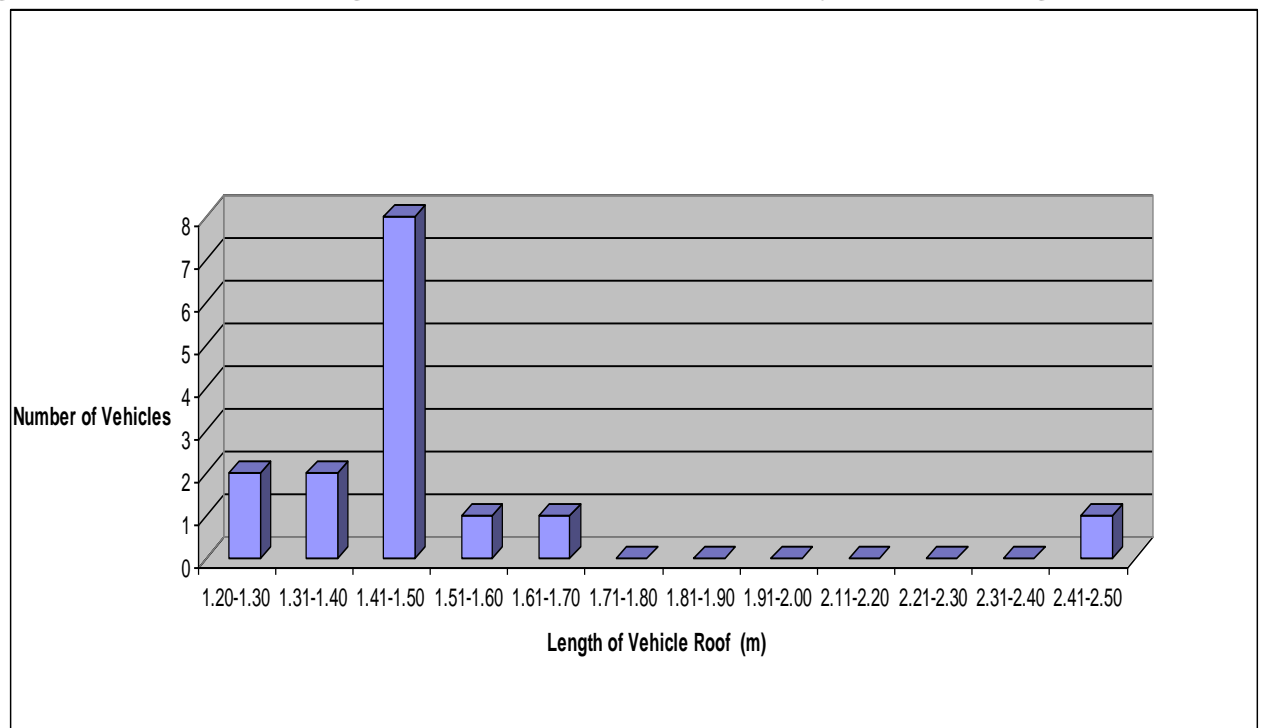

Figure 4: A Chart Showing the Number of Vehicles Surveyed to the Ranges of their Length. 
Based on this result, a rotor diameter of $0.69 \mathrm{~m}$ was chosen for the design.

The Design data:

Power coefficient $\mathrm{C}_{\mathrm{p}}=0.3$

Height of the blade $\mathrm{H}=0.25 \mathrm{~m}$

Width of the blade $\mathrm{r}=0.3 \mathrm{~m}$

Density of air at $20^{\circ} \mathrm{C} \rho=1.2 \mathrm{Kg} / \mathrm{m}^{3}$

\subsection{Estimated power output}

The design of the vehicular wind energy converter inlet is for the amplification of the wind speed before it gets to the blades.

From the continuity equation, mass of air entering is equal to the mass hitting the rotor blades.

Mathematically:

$$
\rho A_{1} V_{1}=\rho A_{2} V_{2}
$$

Since density $\rho$ is constant, $V_{2}=\frac{A_{1} V_{1}}{A_{2}}$

Where,

$A_{1}=$ External area of the inlet, $A_{2}=$ The area of the inner end of the inlet, $V_{1}=$ The initial speed of the wind before entering the inlet of the device, $V_{2}=$ The speed of the wind at the rotor blade.

The outer area of the device inlet: $A_{1}=$ length $\times$ Breath $=0.5 \times 0.27=0.135 \mathrm{~m}^{2}$

The inner end of the device inlet: $\mathrm{A}_{2}=$ length $\times$ Breath $=0.359 \times 0.27=0.09693 \mathrm{~m}^{2}$

Recall,

$$
V_{2}=1.4 V_{l}=\text { The speed of the wind at the rotor blade. } 5 \text { a }
$$

Estimated extractable power by the vehicular Wind Energy Converter: $\mathrm{P}=1 \frac{1}{2} \mathrm{C}_{\mathrm{p}} \rho \mathrm{rH} V_{2}{ }^{3}$

Estimated Energy: Pe $(\mathrm{KW}-\mathrm{h})=$ Estimated power $(\mathrm{P}) \times 3600$ secs

\section{Result}

The estimated power output for this device was modeled and the result is shown in the graph below.

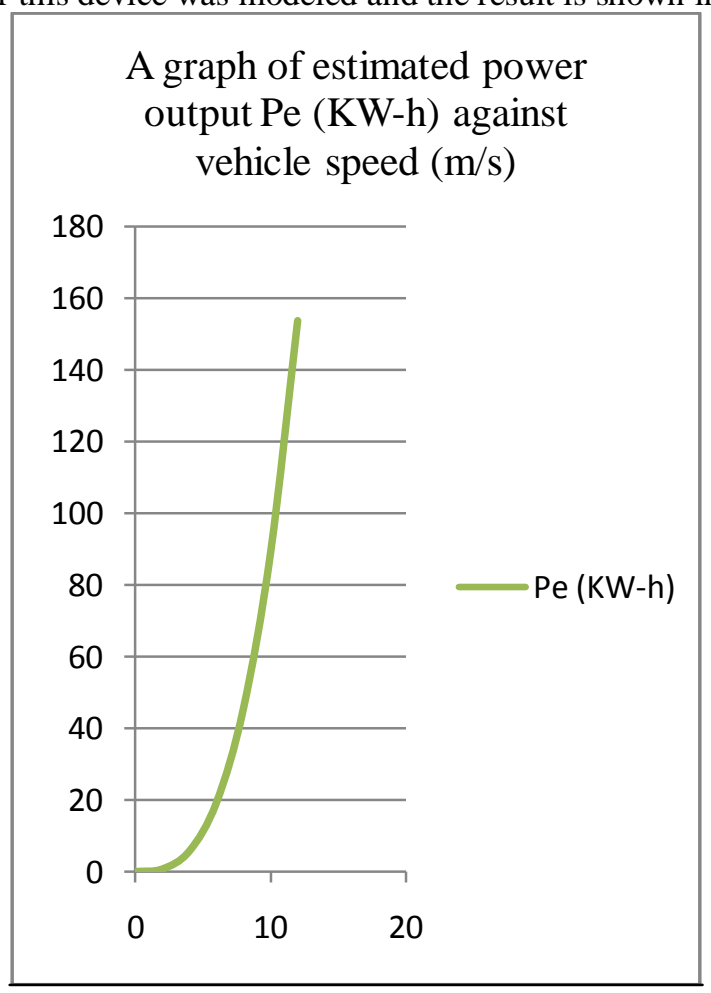

Fig 5: A graph of estimated power $(\mathrm{KW}-\mathrm{h})$ against Vehicle speed $(\mathrm{m} / \mathrm{s})$ for $\mathrm{Cp}=0.2$ 


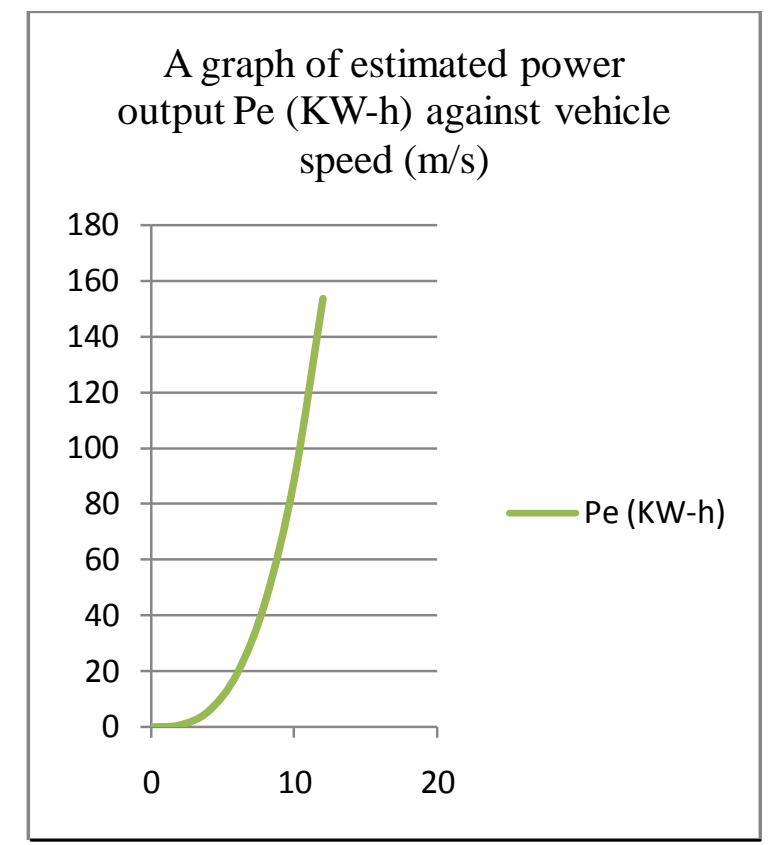

Fig 6: A graph of estimated power $(\mathrm{KW}-\mathrm{h})$ against Vehicle speed $(\mathrm{m} / \mathrm{s})$ for $\mathrm{Cp}=0.3$

\section{Discussion}

The energy demand of most Electric Vehicle ranges between $(12$ - 37) KW-h [10]. Chrysler Electric Vehicles have battery capacity of $200 \mathrm{KW}$ and require electrical energies ranging between (26 -27) KW-h to run. From the result obtained from the numerical model shown in Fig 5 and Fig 6, it is seen that the Vehicular Wind Energy Converter develops at $7 \mathrm{~m} / \mathrm{s}$ for a $\mathrm{Cp}=0.2$ an energy of $30.5 \mathrm{KW}-\mathrm{h}$ and at $6 \mathrm{~m} / \mathrm{s}$ for a $\mathrm{Cp}=0.3$, an energy of $28.8 \mathrm{KW}-\mathrm{h}$.

\section{Conclusion}

From the modeled estimated wind power, it is seen that the vehicular wind energy converter has great potential to be the solution to the problem of the sustainability of electric energy in Electric Vehicles and coating its surface a solar panel will increase the electrical energy available for charging its batteries.

\section{References}

[1] http://en.wikipedia.org/wiki/Electric_car, Retrieved $18^{\text {th }}$ of September, 2012

[2] http://en.wikipedia.org/wiki/wind turbine, 2008.

[3] Ragheb, M., Vertical Axis Wind Turbine, 2011, 1.

[4] Uguru-Okorie, D.C. 2009. The design and construction of a vehicular wind energy converter, MSc thesis, University of Ibadan, Nigeria, 2009.

[5] Savonius SJ, The S-rotor and its applications. Mechanical Engineering ,53 (5), 1931, 333 - 338.

[6] Sathyajith Mathew, Wind Energy Fundamentals (Netherlands: Springer-Verlag Berlin Heidelberg, 2006 ), 107 - 111.

[7] A.Y. Qasim1, R. Usubamatov and Z.M. Zain, Test of Impeller Type Vawt in Wind Tunnel. Journal of Sustainable Energy \& Environment, 3, 2012, 19-23.

[8] Saha, U.K.and Rajkumar, M. Jaya, On the performance analysis of Savonius rotor with twisted blades. Renewable Energy, 31, (2006), Elsevier Ltd. doi:10.1016/j.renene.2005.08.030, 2005.

[9] Andersen, P. D., Technological Innovation in the Danish Wind Turbine Industry: (In Danish) Samfundslitteratur, Copenhagen, 1993.

[10] http://en.wikipedia.org/wiki/Smart_electric_drive, Retrieved $22^{\text {nd }}$ of September, 2012

[11] Energy Commission of Nigeria: Renewable energy master plan, (Nov. 2005), p87-94. 